\title{
Wireless In vivo Biofuel Cell Monitoring
}

L. Di Trocchio, C. Carucci, K.R. Sindhu, C. Morel, J.-L. Lachaud, S. Bichon, S. Gounel, N. Mano, C. Boiziau, C. Dejous, A. Kuhn, and S. Hemour, Senior Member, IEEE

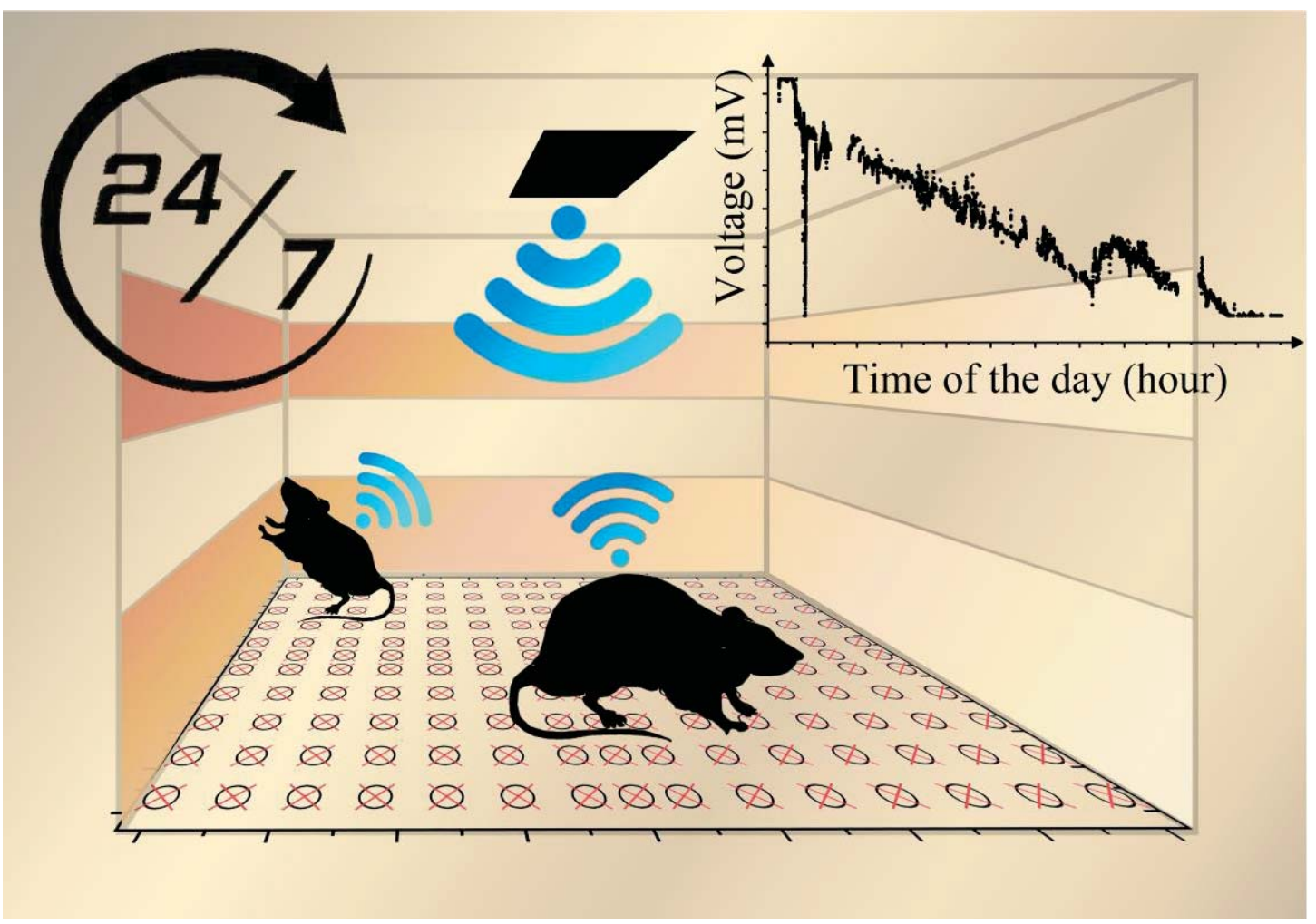

The novel wireless in vivo biofuel cell monitoring setup. The animal, wearing a special design jacket embedding an RFID wearable antenna, is free to move inside the cage, while the open circuit voltage delivered by an implanted glucose $/ \mathrm{O}_{2}$ biofuel cell is continuously, wirelessly monitored.

\section{Take-Home Messages}

- This work presents a light, batteryless, and wireless strategy to continuously monitor a biofuel cell implanted in a laboratory rodent using a Frequency Identification (RFID) link.

- The proposed telemetry system successfully monitored a glucose/O2 biofuel cell continuously in vitro and in vivo over a 24-hour cycle (one day and night).

- The targeted biological application is the study of an implanted glucose/O2 biofuel cell in a real-case scenario involving a living laboratory rodent.

- The main breakthrough of this work is that the passive and lightweight wearable telemetry system allows the monitoring of the biofuel cell while keeping the animal free to move inside its cage, allowing long term measurement.

- A very good agreement between the in vitro and in vivo measurements was observed, evidencing the resilience of our system to the animal typical behavior. 


\title{
Wireless In vivo Biofuel Cell Monitoring
}

\author{
L. Di Trocchio, C. Carucci, K.R. Sindhu, C. Morel, J.-L. Lachaud, S. Bichon, S. Gounel, \\ N. Mano, C. Boiziau, C. Dejous, A. Kuhn, and S. Hemour, Senior Member, IEEE
}

\begin{abstract}
Enzymatic reactions involving glucose hold the potential for building implantable biosensors and embedded power generators for various medical applications. While Biofuel cells (BFCs) such as enzymatic glucose $/ \mathrm{O}_{2}$ are ensured to benefit from abundant chemical resources that can be harvested in the immediate environment of the human body, the highly critical in vivo kinetics of biofuel cell is not yet fully understood. Unfortunately, existing solutions for real-time monitoring of the reaction on rodents are not possible today, or too bulky, which has a biasing impact on the animal behavior. This work presents a light, battery-less, and wireless strategy to continuously monitor a BFC implanted in a laboratory rat using a Frequency Identification (RFID) link. An extremely lightweight and flexible tag antenna of footprint lower than $10 \mathrm{~cm}^{2}$ is presented with communication capability above $60 \mathrm{~cm}$ in field environment. The operational capabilities are demonstrated with a 24-hour continuous monitoring of an enzymatic glucose $/ \mathrm{O}_{2}$ reaction, both in vitro and in vivo.
\end{abstract}

Keywords - RFID tags, biofuel cell, wearable sensors, in vitro, in vivo.

\section{INTRODUCTION}

$\mathrm{T}_{\mathrm{b}}$ HE research of a suitable alternative to bulky batteries to power Electronic Medical Devices (EMDs) is nowadays one of the most important research topic in bioelectronics, in particular to power Implanted Medical Devices (IMDs) [1-5]. Batteries are energy inefficient, unsustainable and need to be recharged/replaced, demanding surgery in case of implants. Moreover, batteries often occupy a larger volume than the sensor itself, limiting the device miniaturization, critical to place the implant at the right location of the body with minimum biological tissue displacement [6]. A possible solution consists in transferring the power wirelessly from a source placed outside of the body, commonly using optical [7, 8], ultrasonic [9, 10] or Radio Frequency (RF) [11-15] links. However, these systems need the constant presence of an external power source, which has to be coupled to the implant, implying permanent additional stress for the patient. To avoid the continuous presence of the transmitter,

Manuscript submitted on December $10^{\text {th }}, 2019$. This work has received financial support from the French State in the frame of the "Investments for the future" Programme IdEx Bordeaux (ANR-10-IDEX-03-02), the ANR (Bio3, ANR-16-CE19-0001-01, animal experimentation and salary of $\mathrm{CM}$ ). KRS and LDT received a doctoral fellowship from LabEx AMADEus (ANR-10-LABX-0042-AMADEUS) and Univ. Bordeaux.

L. Di Trocchio, JL. Lachaud, C. Dejous and S. Hemour are with IMS, Univ. Bordeaux, CNRS, Bordeaux INP, UMR 5218, 33400, Talence, France. (e-mail: luigi.ditrocchio@gmail.com, jean-luc.lachaud@imsbordeaux.fr, dejous@u-bordeaux.fr, simon.hemour@u-bordeaux.fr ).

C. Carucci and A. Kuhn are with ISM, Univ. Bordeaux, CNRS, Bordeaux INP, UMR 5255, 33600, Pessac, France (e-mail: cristina.carucci@unica.it, kuhn@enscbp.fr ).

S. Bichon, S. Gounel, N. Mano are with CRPP, Univ. Bordeaux, CNRS, UMR 5031, 33600, Pessac, France (e-mail: sabrina.bichon@crpp.cnrs.fr, sebastien.gounel@crpp.cnrs.fr, nicolas.mano@crpp.cnrs.fr ).

K.R. Sindhu C. Morel, and C. Boiziau are with Inserm, Univ. Bordeaux, U1026, Laboratory for the Bioengineering of Tissues, F-33000 Bordeaux, France (e-mail: sindkr@gmail.com, chloe.morel77@gmail.com, claudine.boiziau@inserm.fr ). autonomous powering approaches can be suitable alternatives. By harvesting the energy from the ambient environment in many different ways [3,4] those microsystems may provide an attractive alternative to batteries.

Biofuel Cells (BFCs) offer one of the most interesting powering approaches, converting biochemical fuels into electricity thanks to biochemical reactions [16, 17]. In particular enzymatic glucose $/ \mathrm{O}_{2}$ BFCs harvest energy directly from living organisms, using often specially designed enzymes $[16,18,19]$ coated on the anode and cathode of the BFC.

Since glucose and water are abundant in biological environment, e.g. in the human body, the IMDs could be powered by the body's own resources, in a fully renewable way [20]. The design of BFCs is also flexible, since the electrodes can be shaped as required by the designer [2023]. Some BFCs could power wireless electronic circuits, [24-26], but they were too bulky to be implanted. For a given electrode volume, porous surfaces can increase the output power. For example, 3D porous gold electrodes with controllable and defined pore sizes and thicknesses [27-29], have reached power densities above $100 \mu \mathrm{W} / \mathrm{cm}^{2}[20,30$, $31]$. Moreover, due to the dependence of the output power of the glucose biofuel cells on glucose concentration [20], the enzymatic reaction can be used as a sensor, to monitor the glucose concentration in the organism [20, 32-34]. Unfortunately, the limited lifetime of these devices and the possible long-term biocompatibility issues are important challenges that have to be faced to improve BFCs capable to successfully power an IMD [35]. Toward progress in reliability and lifetime, continuous monitoring of the BFC output is of high importance to get a better understanding of the kinetics of the reaction. This must be done in a real application context, i.e. in vivo, and without affecting or impeding the patient with wires.

BFCs have been studied in vivo, in several animal species $[36,37]$, mostly in laboratory rodents, like rats [38, 39]. In most cases, the monitoring was done by using wires, and 
the animal was kept under anesthesia or put in a small cage, to prevent or limit any movement. Some efforts have been made to improve the animal comfort and enable measurement in real living conditions with a wireless link. A BFC implanted in a rabbit was monitored for two months, using a Bluetooth radio [40], but it required batteries and led to impairment in usual activities of the animal due to the bulkiness of this kind of power source.

Alternatively, Ultra High Frequency (UHF) Radio Frequency Identification (RFID) technology appears as an elegant way for monitoring signals, as the telemetry circuit is wirelessly powered. The RFID Integrated Circuit (IC) can embed Analog-to-Digital Converter (ADC), sensors capabilities and/or external sensor interfaces, which allow the data processing directly in the RFID tag [41]. This technology permits incredible flexibility to the tags and countless applications, having the sensed data independent from the path. It has been deployed in numerous applications (e.g. body temperature monitoring [41-43], sometimes with on-chip temperature sensors [44, 45], vital signs monitoring systems like ECG [46] or EEG [47], relative plantar pressure [48], bed-regress tracking in elderly people [49], breath monitoring [50], pH skin sensor [51], etc.)

The only constraint of such systems is that the sensor tag has to be within the Reading Range (RR) of the remote telemetry reader [52]. A minimum necessary power to turnon the circuit has to be provided, limiting the RR. This is especially critical when dedicated energy is needed for power-hungry functions such as ADC or sensors data processing. As a matter of fact, the wearable antenna plays a critical role in the tradeoff: (i) reading range vs. (ii) unaffected animal behavior. Reading range is addressed by maximizing the realized gain, by matching the complex input impedance of the antenna to the one of the chip, and optimizing the radiation characteristics of the antenna. However unaffected animal behavior (also called "wearability" or "comfortable wearing") is mainly obtained by reducing the overall size of the antenna.

As a path towards solving this tradeoff, the epidermal electronics concept brings radical change to the wearable antenna design process, by prioritizing extra lightweight electronic payload, to ensure long-term (weeks) wearability $[53,54]$. This category of devices consists in very thin, single-layer foldable antennas, attached to the skin at a maximum of one millimeter from it, by means of a flexible (and sometimes elastic [54]) substrate. Typical realized gain of such antenna [42] is in the order of $-15 \mathrm{~dB}$ taking into account a homogeneous human model $\left(\varepsilon_{\mathrm{r}}=41.2\right.$, $\sigma=0.95 \mathrm{~S} / \mathrm{m}$ ), which is very low, as compared to ordinary antennas, mainly because of the presence of human tissues.

This work presents, for the first time, a passive RFID telemetry system for BFC in vivo monitoring. A special care is given to the high dielectric constant and the dielectric losses of the rat tissues, which influence the input impedance and limit the radiation characteristics of the antenna. The proposed monitoring system is illustrated in Fig. 1: After having performed the surgery to implant subcutaneously the two BFC electrodes, the rat, placed

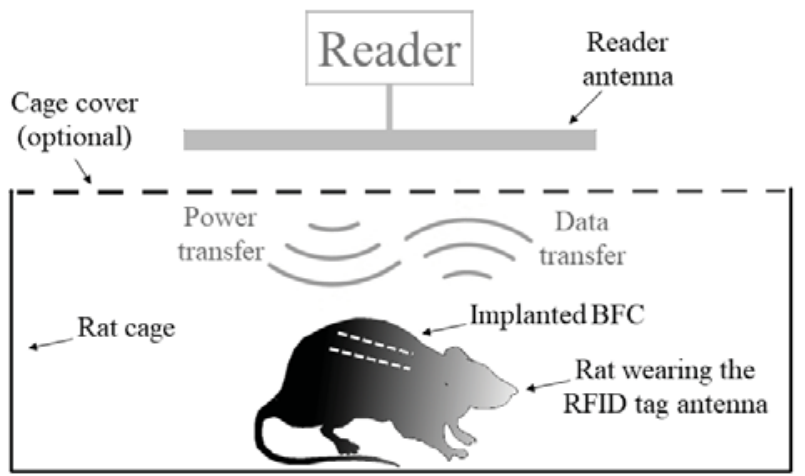

Fig. 1. Setup of the proposed telemetry system.

inside the cage, wears a jacket, embedding the RFID sensor tag. On the top of the cage, the RFID reader antenna powers and interrogates the tag. Thanks to this setup, the animal is continuously monitored while it is free to move inside the cage. A cover (of non-conductive material) may be used to secure the rat inside the cage.

The article is organized as following: in Sec. II the designed antennas are presented, and the RFID link is validated. The in vitro and in vivo characterizations of the BFC-antenna setup are then described in Sec. III and the achieved results are reported in Sec. IV.

\section{RFID TAG-BASED MONITORING SETUP}

\section{A. Tag antenna design}

To monitor and record the energy produced by the implanted BFC, an ADC-embedded silicon RFID IC (AMS-SL900A) was selected [44]. This IC has two analogical inputs that can be used to connect the electrodes. Moreover, it has a built-in temperature sensor, which may allow the monitoring of the animal temperature during the experiment (not implemented in this study), all without any external battery. The chip input impedance is $Z_{c}=123$ $\mathrm{j} 303 \Omega$ at UHF-RFID frequencies and has a sensitivity $\mathrm{p}_{\text {min }}=-6.9 \mathrm{dBm}$ in battery-less mode. Moreover, the ADC is capable of converting voltages between 310 and $620 \mathrm{mV}$, covering thus most of the voltage range of a BFC [55].

Since the SL900A IC has an unbalanced RF configuration, dipole-like structures generally employed $[56,57]$ are sub- optimal. Therefore, a folded monopole structure was designed, which is represented on Fig. 2 a. The antenna was terminated by a loop, to enhance the inductive behavior required, and the width of the far-end side was increased, to improve the tag bandwidth. Additionally, a lumped inductor was inserted, to ease the impedance matching of the chip. Soldering pads for the IC and the electrode connector were inserted onto the ground, minimizing the discontinuities of the surface current (Fig.2a), allowing the connection of the BFC electrodes with minimum tag dimensions. Finally, a lumped capacitor $(2.2 \mu \mathrm{F})$ was implemented at the output of charge pump's rectifier to allow stable ADC operation and enhance the RR [44].

To insure high wearability, a flexible and low-weight $40 \mu \mathrm{m}$ thick $\operatorname{Kapton} \AA \quad\left(\varepsilon_{\mathrm{r}}=2.94, \tan \delta=0.0012\right) \quad$ was 


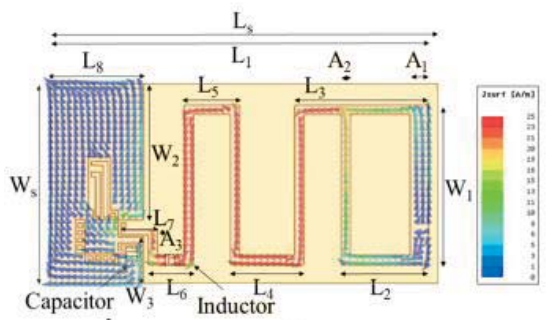

(a)

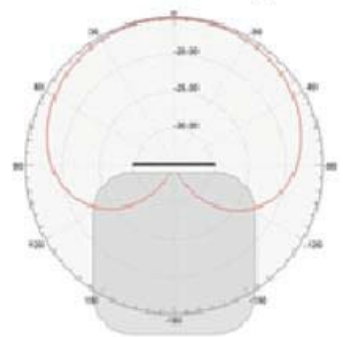

(c)

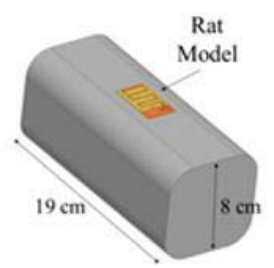

(b)

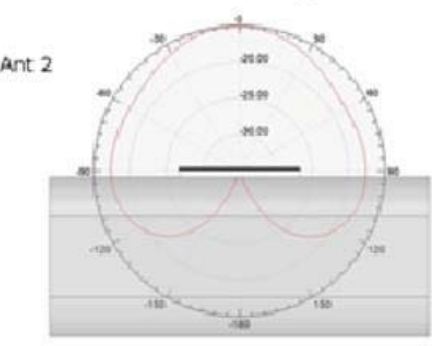

(d)
Fig. 2. The wearable monopole antenna: Antenna shape and surface current density (a) and the simulation box (b). Antenna \#2 position and radiation pattern is given for the two vertical central planes in (c) and (d).

selected as substrate and $30 \mu \mathrm{m}$ copper was used as metal.

The resulting structure, as on Fig. 2a, has been optimized using the HFFS (Ansoft, Pittsburgh, PA) simulation tool. The rat was modelled as a parallelepiped, having dimensions 19x8x8 $\mathrm{cm}^{3}$, with rounded edges (Fig. 2b). The material used was defined as a balanced average of all body tissues at $900 \mathrm{MHz}\left(\varepsilon_{\mathrm{r}}=55.03, \sigma=1.01 \mathrm{~S} / \mathrm{m}\right)$ [58], located in the midrange of the UHF-RFID band (860-960 MHz). Since the dielectric characteristics of biological tissues are almost constant over this band [59], the material values were kept constant as a function of frequency.

The flexible antenna is specified for two different cases. The first one, "Antl" (Fig 2b) is the classical epidermal electronic case, the antenna is placed at a distance of $1 \mathrm{~mm}$ from the skin to insure high-wearability. In simulations, $\varepsilon_{\mathrm{r}}=1$ was used as relative permittivity of the medium between the antenna and the rat. In the second case, in order to simulate a real-case scenario, (“Ant2") (Fig 2c, d), a patch made of bio-silicone $\left(\varepsilon_{\mathrm{r}}=2.2, \sigma=0.005 \mathrm{~S} / \mathrm{m}\right), 3 \mathrm{~mm}$ thick, was placed between the antenna and the rat. This is because sticking the antenna directly on the skin of the animal can cause skin inflammation [60]. For the sake of completeness, Fig. $2 \mathrm{c}$ and $2 \mathrm{~d}$ show the resulting far-field radiation patterns of Ant2 (the antenna is being operated in mid-field and far-field). Table I shows the dimensions in $\mathrm{mm}$ for the two antennas. The two selected inductors were $8.2 \mathrm{nH}$ and $16 \mathrm{nH}$ for Ant1 and Ant2 respectively.

Fig. 3 shows the simulated reflection coefficient of the two antennas, taking into account the chip impedance as reference, and the maximum realized gain. This parameter is defined as $G_{r}^{\max } \cdot \tau$ where $G_{r}^{\max }$ is the maximum value of the antenna gain and $\tau$ is the power transmission coefficient. The two antennas were designed to operate in the $915 \mathrm{MHz}$ band. As Fig. 3 shows, the antennas resonate at this frequency, they have a $-10 \mathrm{~dB}$ bandwidth of 64.3 and
TABLE I

THE DIMENSIONS (IN MM) OF THE DESIGNED ANTENNAS.

\begin{tabular}{ccccccccc}
\hline \hline Case & $\mathrm{A}_{1}$ & $\mathrm{~A}_{2}$ & $\mathrm{~A}_{3}$ & $\mathrm{~W}_{\mathrm{s}}$ & $\mathrm{W}_{1}$ & $\mathrm{~W}_{2}$ & $\mathrm{~W}_{3}$ & $\mathrm{~L}_{\mathrm{s}}$ \\
\hline Ant1 & 2 & 1 & 0.5 & 25 & 18.4 & 18.8 & 45 & 43.5 \\
Ant2 & 2 & 1 & 0.5 & 21.5 & 17.2 & 14.7 & 42 & 41 \\
\hline Case & $\mathrm{L}_{1}$ & $\mathrm{~L}_{2}$ & $\mathrm{~L}_{3}$ & $\mathrm{~L}_{4}$ & $\mathrm{~L}_{5}$ & $\mathrm{~L}_{6}$ & $\mathrm{~L}_{7}$ & $\mathrm{~L}_{8}$ \\
\hline Ant1 & 12 & 5 & 17 & 8 & 6 & 4.9 & 3.95 & 10.1 \\
Ant2 & 9.5 & 5 & 14.5 & 8 & 6 & 4.9 & 3.95 & 10.1 \\
\hline \hline
\end{tabular}

65.8 MHz, for Ant1 and Ant2, respectively, and a $-3 \mathrm{~dB}$ bandwidth that covers all the UHF-RFID spectrum, thanks to tissue losses.

Fig. 3 also shows the behavior of the maximum realized antenna gain with respect to the frequency. As a result, for both structures, the gain is quite flat over the antenna bandwidth, with values of the order of $-15 \mathrm{~dB}$, similar to other epidermal electronic antennas. Thanks to the longer separation between the structure and the biological tissues, Ant 2 offers a gain slightly higher than Ant1, while being smaller, as Table I evidences. This is important because the design priority was put on the miniaturization of the structures, while keeping a gain that insures a RR large enough to monitor a rat in its cage.

As a final remark, since the horizontal segments of the antennas are not participating in the radiation process, the antennas can be easily adapted to resonate at all the worldwide UHF-RFID bandwidths, by adjusting its overall width, without changing the radiation characteristics.

Starting from the simulation, the resulting RR is obtained by implementing the following expression [61]:

$$
R R=\frac{\lambda_{0}}{4 \pi} \sqrt{\frac{E I R P \cdot G_{r} \cdot \tau}{p_{\min }},}
$$

where $G_{r}$ is the gain of the receiver tag antenna, $\tau=1-\left|S_{11}\right|^{2}$ is the tag power transmission coefficient, $p_{\min }$ is the sensitivity of the RFID chip and EIRP is the equivalent isotropic radiated power. By assuming the maximum allowed radiated power in the US $(\mathrm{EIRP}=4 \mathrm{~W})$, the resulting maximum $R R$ is $R R_{1}=63 \mathrm{~cm}$ and $R R_{2}=65 \mathrm{~cm}$ for Ant1 and Ant 2 respectively, large enough to allow the rat monitoring.

\section{B. RFID link validation}

The tag Ant 2 was built by chemical etching of copper on Kapton ${ }^{\circledR}$ substrate. The full structure, including the components, has a weight of only $0.6 \mathrm{~g}$. The RFID setup was completed with a $5 \mathrm{~dB}$ gain circularly polarized antenna (Abracon APAES915R80C16-T) and a reader (AMS Radon), emitting $1 \mathrm{~W}$. The reader was also programmed to measure the voltage delivered by the BFC.

The maximum tag $\mathrm{RR}$ was estimated by fixing the receiver position and increasing the reader-antenna distance in different conditions until ADC reading failed to be wirelessly recovered. The resulting RR was above $60 \mathrm{~cm}$, in agreement with the simulation.

In order to verify the complete coverage of a surface equivalent to a typical rat cage, a specifically designed measurement setup was defined. A half PET bottle, $0.5 \mathrm{~mm}$ thick, was filled with minced bovine meat, at room 


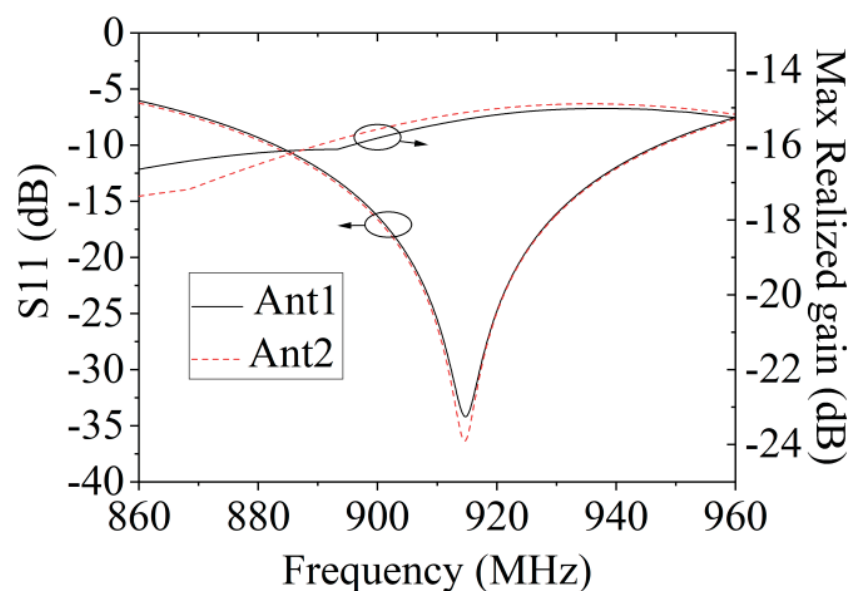

Fig. 3. Simulated reflection coefficient and maximum realized gain for the two designed structures, with respect to the frequency.

temperature $\left(21-23{ }^{\circ} \mathrm{C}\right)$, to simulate the animal body tissue. On its side, the tag antenna was placed. Moreover, a $3 \mathrm{~mm}$ silicone patch was placed between the bottle and the antenna, to emulate the real case scenario. A grid, having the external dimension of $40 \times 28 \mathrm{~cm}^{2}$, typical of a rat cage, was drawn and the bottle position was swept in order to verify the communication between the tag and the reader. The reader antenna was placed on the top of the grid, at a distance of $40 \mathrm{~cm}$ from the cage bottom.

Two rat positions were taken into account, with the bottle axis parallel and perpendicular to the ground, in order to mimic the two assumed most frequent positions of the rodent inside its cage. For the perpendicular position, the tag antenna was always oriented facing the reader. Fig. 4 illustrates the measurement setup and the detected points. As a result, for all measurement points, for both antenna positions, the RFID link was established. Therefore, the rat should be detectable in the whole cage and in any position.

\section{IN VITRO AND IN VIVO BIOFUEL CELL MONITORING}

Glucose $/ \mathrm{O}_{2}$ biofuel cells take advantage of the oxidation of glucose and reduction of molecular oxygen to water in order to produce electrons, as follows:

$$
\begin{aligned}
& \text { Anode side: } \mathrm{C}_{6} \mathrm{H}_{12} \mathrm{O}_{6} \rightarrow \mathrm{C}_{6} \mathrm{H}_{10} \mathrm{O}_{6}+2 \mathrm{H}^{+}+2 e^{-} \\
& \text {Cathode side: } \mathrm{O}_{2}+4 \mathrm{H}^{+}+4 e^{-} \rightarrow 2 \mathrm{H}_{2} \mathrm{O} \\
& \text { Global reaction: } 2 \mathrm{C}_{6} \mathrm{H}_{12} \mathrm{O}_{6}+\mathrm{O}_{2} \rightarrow 2 \mathrm{C}_{6} \mathrm{H}_{10} \mathrm{O}_{6}+\mathrm{H}_{2} \mathrm{O} \text {. }
\end{aligned}
$$

At the anode side, the glucose $\left(\mathrm{C}_{6} \mathrm{H}_{12} \mathrm{O}_{6}\right)$ is electrooxidized, producing gluconolactone $\left(\mathrm{C}_{6} \mathrm{H}_{10} \mathrm{O}_{6}\right)$, two hydrogen ions and two electrons. These electrons flow towards the cathode side, where they combine with oxygen and hydrogen ions to produce water by a reduction process. The produced electron flow, passing through a load, generates the energy needed to power the IMD. Glucose oxidase is the most commonly used anodic enzyme [62] while Bilirubin Oxidase is preferentially used on the cathodic side because of its high tolerance to chloride ions and stability near neutral $\mathrm{pH}$ [63]. To properly connect the redox centers of enzymes to the electrode surface, dedicated redox polymers are used if needed as a shuttle of electrons

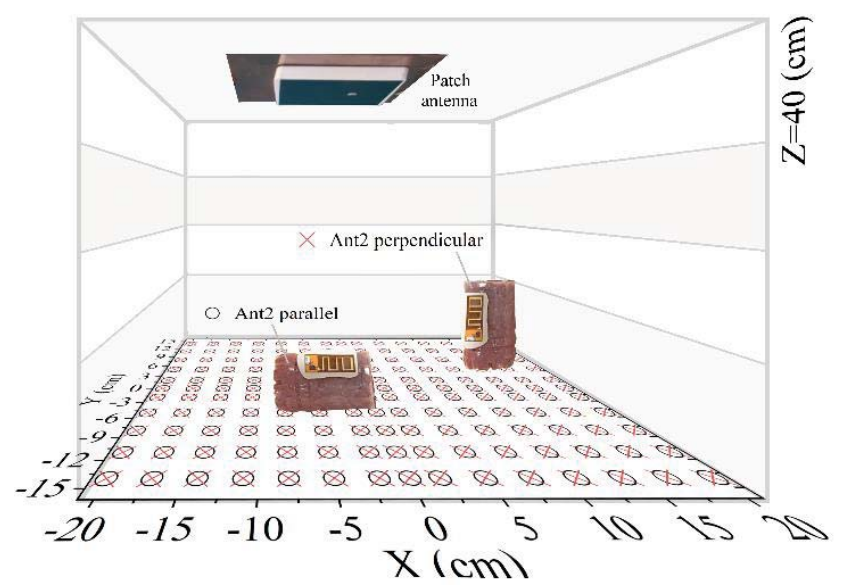

Fig. 4. RFID link validation: wireless sensor telemetry has been tested for two antenna configurations (parallel and perpendicular to the Patch antenna) while mounted on a PET bottle filled with ground beef. Red and black scatter show where readings have been validated (total coverage of the surface corresponding to the cage).

to improve the electron transfer [64].

After having validated the link and the measurement capability, the continuous monitoring of the BFC was performed in vitro and in vivo and the resulting voltage values were compared. The following section presents the performed measurements, including the BFC preparation with macroporous electrodes and the enzyme immobilization.

\section{A. Electrodes and enzyme preparation}

\section{1) Fabrication of macroporous gold electrodes}

Cylindrical macroporous gold electrodes were prepared using a procedure described in previous work [65]. In brief, a colloidal template made out of silica beads $(d=1170 \mathrm{~nm})$ was first generated at the gold wire surface by following a reported procedure. Subsequently metallic gold is electrodeposited in the void space between the silica beads. After dissolution of the template a porous matrix is obtained. The thickness of the electrodes can be controlled by the number of macroporous layers that are deposited. This is achieved by following the periodic current oscillations during the potentiostatic deposition of the metal. Macroporous gold electrodes of 11 half layers thickness were used for all the experiments in vitro and in vivo.

\section{2) Immobilization of enzymes in the macroporous}

\section{electrodes}

Bilirubin Oxidase (BOD) from Magnaporthe oryzae is able to undergo Direct Electron Transfer because the active redox center of the enzyme is close enough to the outer surface of its protein shell. In this case, electrons can directly be transferred from the electrode to the enzyme. To improve the interaction between the enzyme and the gold surface, and thus increase the rate of electrons transfer, we designed and produced a mutant of this enzyme bearing a cysteine residue, well known to strongly attach to gold surfaces [66]. The mutant BOD has then been directly immobilized onto the porous electrode by a coating process previously described [67]. On the contrary, Glucose Oxidase $(\mathrm{GOx})$ is not able to promote direct electron 


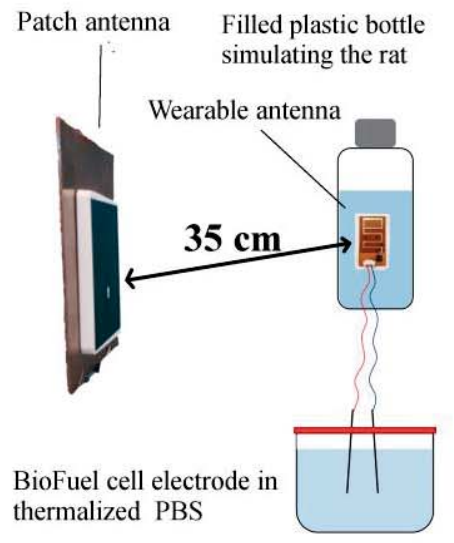

(a)

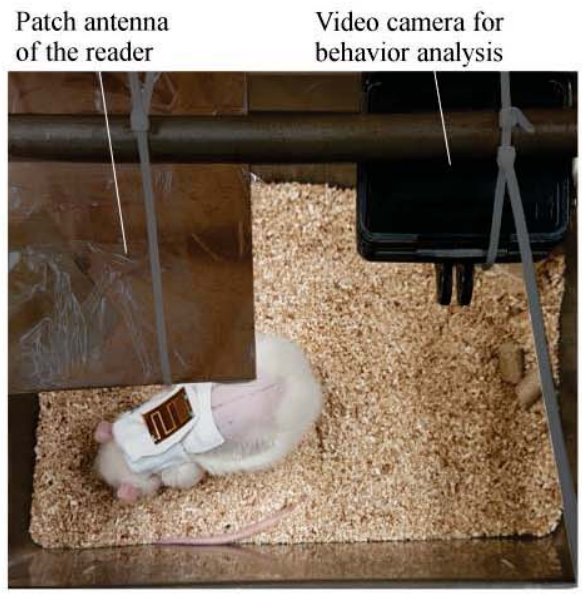

(b)

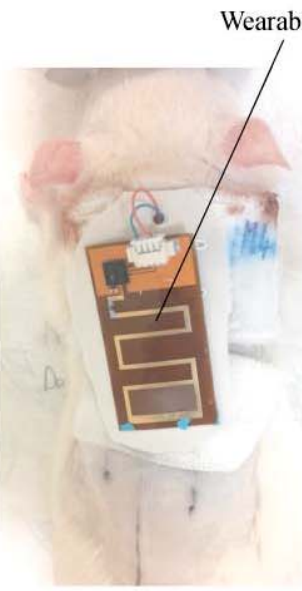

(c)

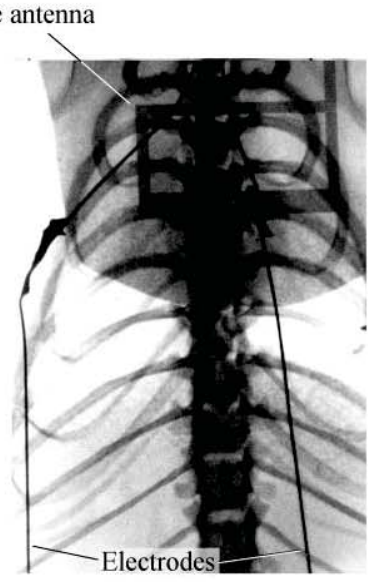

(d)

Fig. 5. In vitro measurement setup (a), a plastic bottle partially filled with water simulates the body tissue to match the antenna, and the in vivo BFC monitoring setup (b). The chip is connected to the two electrodes subcutaneously implanted (c). X rays images of the rat just after the implantation (d). Cathode is red (left implanted electrode); Anode is blue (right implanted electrode).

transfer because its active centers are deeply buried within the protein. In that case, a redox mediator is needed to shuttle electrons between the active centers of the GOx and the electrode surface. Polycationic osmium based-redox polymers are one of the most efficient redox mediators allowing the connection of the redox centers of GOx to the electrode surface while immobilizing the enzyme on the electrode. The immobilization is achieved by mixing GOx, which is polyanionic at neutral $\mathrm{pH}$, with the polycationic osmium based redox polymer in the presence of a chemical cross-linker (poly (ethyleneglycol) diglycidyl ether, PEGDGE) to further strengthen the formed hydrogel [68, 69]. As a result, the GOx molecules are surrounded by osmium complexes that shuttle the electrons exchanged during the oxydo-reduction of the substrate to the electrode surface, regardless of the orientation of the enzymes. The anodic redox polymer used in this work was an osmium based redox polymer with a redox potential of -20 $\mathrm{mV} / \mathrm{AgAgCl}$. The anodic hydrogel was composed of $35 \mathrm{wt} \%$ of GOx from Aspergillus niger, $60 \mathrm{wt} \%$ of PolyVinylPyridine-Os[(1,1-dimethyl-2,2'biimidazole)2-2-[6 methylpyrid-2yl] imidazole $]^{2+/ 3+}$ and $5 \mathrm{wt} \%$ PEGDGE. Once realized, the hydrogel was deposited on the porous electrode surface and let cured for $18 \mathrm{~h}$ at $4{ }^{\circ} \mathrm{C}$. Full details on the polymer synthesis, enzyme production/purification and adduct preparation can be found in our earlier works $[70,71]$.

\section{$B$. In vitro measurements setup}

Before implementing the in vivo, real-case scenario monitoring, the BFC was wirelessly monitored in vitro. Fig. 5a shows the measurement setup. In continuity with the link mapping, the circularly polarized antenna was connected to the RFID reader, emitting $1 \mathrm{~W}$ of power. The wearable antenna (Ant2) was placed on a bottle half-filled with Phosphate-Buffered Saline solution (PBS-137 mM $\mathrm{NaCl}, 2.7 \mathrm{mM} \mathrm{KCl}, 10 \mathrm{mM} \mathrm{Na} \mathrm{HPO}_{4}, 1.8 \mathrm{mM} \mathrm{KH}_{2} \mathrm{PO}_{4}$, pH 7.2), in order to mimic the animal. A $3 \mathrm{~mm}$ thick patch of silicone was placed between the antenna and the bottle.
The BFC electrodes were placed in a temperaturecontrolled oxygenated PBS solution, at $37^{\circ} \mathrm{C}$, to mimic the natural body temperature. $5 \mathrm{mM}$ of glucose were added to the solution, which is the normal glucose concentration in a rat [72].

Finally, the electrodes were connected to the $1 \mathrm{M} \Omega$ input of the embedded ADC (1 $\mathrm{mV}$ resolution), and the voltage of the cell was sampled every 10 seconds to monitor the enzymatic reaction. It was recorded until it reached the minimum detectable value, i.e. $310 \mathrm{mV}$.

\section{In vivo measurement setup}

In order to achieve the in vivo monitoring of the BFC, a pair of modified macroporous gold electrodes was implanted sub-cutaneously in the back of a 12-16 weeks-old Sprague Dawley female rat. Once the implantation was achieved, electrodes were connected to the inputs of the SL900A chip by means of the electrode connector. As for the in vitro study, Ant 2 was used for the experiment. It was glued on a bio-silicone patch and placed on the animal using a commercial jacket for rats (Harvard Apparatus) (Fig.5c).

After surgery, X-ray imaging was performed to confirm the correct position of the electrodes (Fig. 5d). Then the rat was placed inside its cage to recover from the anesthesia and to perform the monitoring. Fig. $5 \mathrm{~b}$ shows the measurement setup. The reader antenna was placed on the cage, at a distance of about $30-35 \mathrm{~cm}$ from the animal. The RFID setup presented in Sec. II.B was used. To monitor the rat movement, a camera was also placed on the top of the cage, alongside the reader antenna.

The open circuit voltage of the BFC was recorded from the end of the surgery (about one hour after the end of the implantation), until the minimum detectable value was reached. The recording time was about 24 hours, recording one measurement every 10 seconds, similarly to the in vitro study. During the whole recording, the animal, inside its cage, was placed in a temperature and humidity controlled room, with the day/night time automatically regulated and food and water ad libitum. 


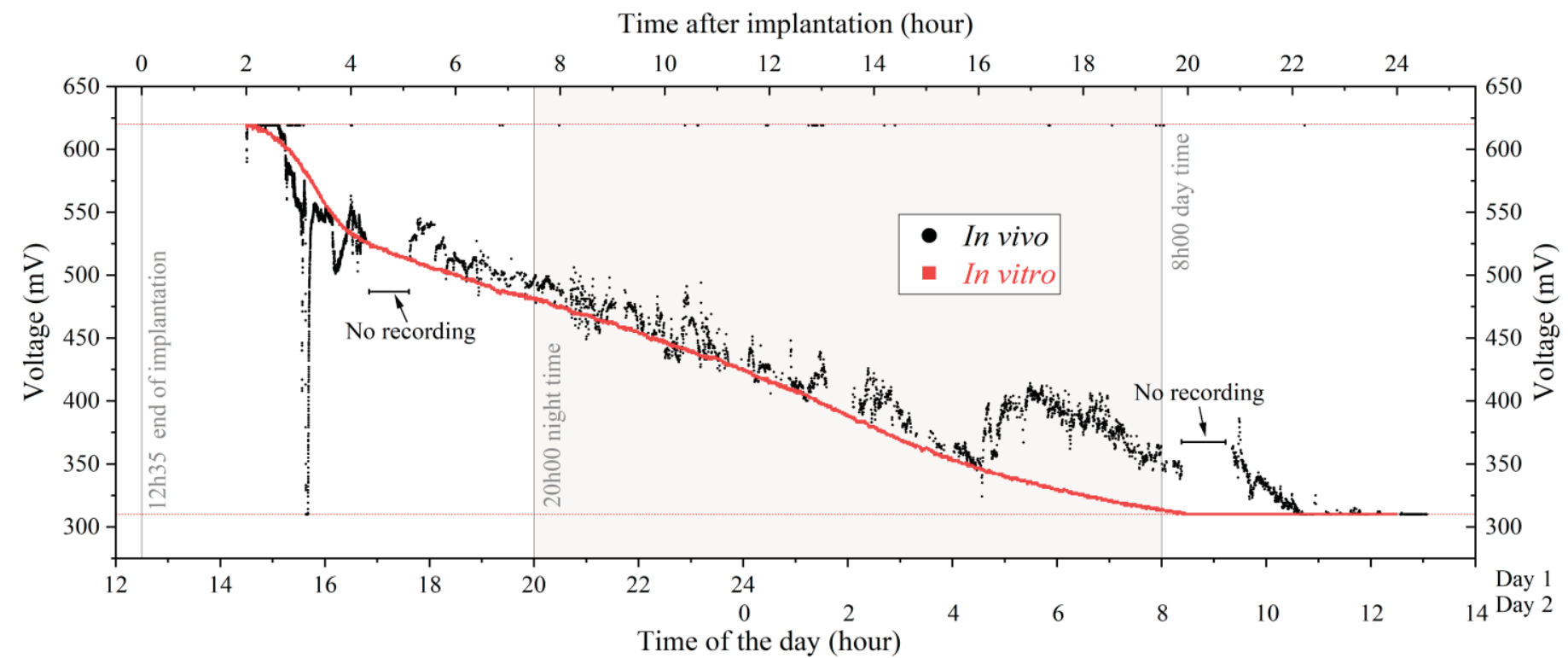

Fig. 6. The in vitro (red curve) and in vivo (black curve) open circuit voltage of the BFC recorded wirelessly.

\section{RESULTS AND DISCUSSION}

Fig. 6 shows the resulting open circuit voltage of the $\mathrm{BFC}$ recorded in vivo (black curve), compared to the in vitro one (red curve). No data were recorded during the first 2 hours because the voltage values were above the working range of the $\mathrm{ADC}$.

Firstly, the in vitro analysis (red curve) shows a regular decrease with two different slopes. A fast voltage decrease is observed between 2 and 4 hours after measurement. Then, the slope is reduced after 4 hours and the voltage decreases regularly until it reaches the minimum detectable value about 20 hours after the in vitro experiment beginning. This overall decay of the open circuit potential may be attributed to $\mathrm{O}_{2}$ depletion in the medium and/or to the denaturation/loss of the enzymes. This question has to be addressed in future studies.

The same general behavior is observed in the in vivo case (black curve). The signal was monitored continuously during the whole experiment duration, validating the wireless measurement setup. The absence of data from about 4.5 to 5.5 and from 20 to 21 hours after the implantation corresponds to the moment when the rat was removed from the cage to perform X-rays and check the position of the electrodes (shown in fig. 5c). Moreover, videos using the camera were recorded during the experiment, for further study of the rat's behavior. A short video in supplementary material (Suppl. S1) shows that the rat was able to move freely.

Interestingly, the in vivo analysis shows a highly comparable behavior, despite more signal noise than the in vitro experiment. The two curves evolve in a very analog way, except late at night and the first two hours of daytime. We hypothesize that the rapid voltage changes might be due to rat micro-movements and/or to electrodes displacement. Regarding the voltage increase about 16 hours after implantation, this is not observed in vitro, and might be due to circadian rhythm modifications of different parameters.
Rats are nocturnal rodents especially active during the night, and are feeding mostly in this period [73]. Modifications of the BFC activity could be also induced by changes in body temperature, glucose concentration or oxygen pressure. According to bibliography, the body temperature is higher during the night and drops at the late night, from 38.5 to $37^{\circ} \mathrm{C}$ [74]; glucose concentration peaks at the beginning of the night $(7 \mathrm{mM})$, slowly decreases during the night $(6 \mathrm{mM})$ and goes up again just before dusk [75]; in reference [76] it is shown that oxygen concentration in tissues peaks during the night, and gradually declines at the end of the night and during daytime. This shows that the recorded signal is not directly associated with a single physiological parameter. However, the unexpected parallel decline of voltage in vitro and in vivo may be an indication that the inflammatory reaction induced by BFC implantation is moderate and does not impair BFC functionality.

Our monitoring system, associated with video monitoring will therefore be a great help to correlate the measured voltage with the rat behavior during the night.

\section{CONCLUSION}

A monopole RFID wearable tag antenna, implementing the SL900A IC, is proposed. Having lightweight $(0.6 \mathrm{~g})$ and compact dimensions $\left(42 \times 21.5 \mathrm{~mm}^{2}\right.$ regarding Ant2), this passive system has a RR of more than $60 \mathrm{~mm}$, allowing the wireless monitoring of a laboratory rat.

The telemetry system successfully monitored a glucose $/ \mathrm{O}_{2}$ biofuel cell continuously in vitro and in vivo. Very good agreement between the two measurements was observed, evidencing good consistency of the BFC signal between the in vitro ideal case, and the in vivo real case scenario.

The proposed battery-less, flexible and lightweight system is thus a first important step towards an alternative to wired telemetry for monitoring a BFC in vivo. 


\section{ETHICAL APPROVAL}

All applicable international, national, and institutional guidelines for the care and use of animals were followed. All procedures performed in studies involving animals were in accordance with the ethical standards of the institution or practice at which the studies were conducted (animal experimentation permission APAFIS\# 164432018072016398155).

\section{ACKNOWLEDGMENT}

Thibaut Koch and the fast prototyping facility of the ThingVA company are to be acknowledged for the early flexible prototype fabrication. The authors would also like to thank the Animal house facility A1 (University of Bordeaux).

\section{REFERENCES}

[1] A. Ben Amar, A. B. Kouki, and H. Cao, "Power Approaches for Implantable Medical Devices," Sensors (Basel, Switzerland), vol. 15, pp. 28889-28914, 2015.

[2] P. M. Lee, Z. Xiong, and J. Ho, "Methods for powering bioelectronic microdevices," Bioelectronics in Medicine, vol. 1, pp. 201-217, 2018.

[3] B. Shi, Z. Li, and Y. Fan, "Implantable Energy-Harvesting Devices," Advanced Materials, vol. 30, p. 1801511, 2018.

[4] T. Ghomian and S. Mehraeen, "Survey of energy scavenging for wearable and implantable devices," Energy, vol. 178, pp. 33-49, 2019

[5] R. Kerley, X. Huang, and D. S. Ha, "Energy Harvesting from the Human Body and Powering up Implant Devices," in Nano Devices and Circuit Techniques for Low-Energy Applications and Energy Harvesting, C.-M. Kyung, Ed., ed Dordrecht: Springer Netherlands, 2016, pp. 147-180.

[6] J. Kim, R. Ghaffari, and D.-H. Kim, "The quest for miniaturized soft bioelectronic devices," Nature Biomedical Engineering, vol. 1, p. 0049,2017

[7] M. Mujeeb-U-Rahman, D. Adalian, C.-F. Chang, and A. Scherer, "Optical power transfer and communication methods for wireless implantable sensing platforms," Journal of Biomedical Optics, vol. 20, pp. 1-9, 9, 2015

[8] A. Saha, S. Iqbal, M. Karmaker, S. F. Zinnat, and M. T. Ali, "A wireless optical power system for medical implants using low power near-IR laser," in 2017 39th Annual International Conference of the IEEE Engineering in Medicine and Biology Society (EMBC), 2017, pp. 1978-1981.

[9] H. Basaeri, D. B. Christensen, and S. Roundy, "A review of acoustic power transfer for bio-medical implants," Smart Materials and Structures, vol. 25, p. 123001, 2016.

[10] R. V. Taalla, M. S. Arefin, A. Kaynak, and A. Z. Kouzani, "A Review on Miniaturized Ultrasonic Wireless Power Transfer to Implantable Medical Devices," IEEE Access, vol. 7, pp. 2092-2106, 2019.

[11] H. Kim, H. Hirayama, S. Kim, K. J. Han, R. Zhang, and J. Choi, "Review of Near-Field Wireless Power and Communication for Biomedical Applications," IEEE Access, vol. 5, pp. 21264-21285, 2017.

[12] J. S. Ho, S. Kim, and A. S. Y. Poon, "Midfield Wireless Powering for Implantable Systems," Proc. IEEE, vol. 101, pp. 1369-1378, 2013.

[13] C. Liu, Y. Guo, H. Sun, and S. Xiao, "Design and Safety Considerations of an Implantable Rectenna for Far-Field Wireless Power Transfer," IEEE Trans. Antennas Propag., vol. 62, pp. 57985806, 2014

[14] L. D. Trocchio, J. Lachaud, C. Dejous, A. Kuhn, and S. Hemour, "High-Q Implantable Resonator for Wireless Power Delivery," in 2018 IEEE International Microwave Biomedical Conference (IMBioC), 2018, pp. 46-48

[15] W. Wang, S. Hemour, and $\mathrm{K}$. Wu, "Coupled Resonance Energy Transfer Over Gigahertz Frequency Range Using Ceramic Filled
Cavity for Medical Implanted Sensors," IEEE Trans. Microwave Theory Tech., vol. 62, pp. 956-964, 2014

[16] X. Xiao, H.-q. Xia, R. Wu, L. Bai, L. Yan, E. Magner, et al., "Tackling the Challenges of Enzymatic (Bio)Fuel Cells," Chem. Rev., vol. 119, pp. 9509-9558, 2019

[17] M. Rasmussen, S. Abdellaoui, and S. D. Minteer, "Enzymatic biofuel cells: 30 years of critical advancements," Biosensors Bioelectron., vol. 76, pp. 91-102, 2016.

[18] N. Mano and A. de Poulpiquet, "O2 Reduction in Enzymatic Biofuel Cells," Chem. Rev., vol. 118, pp. 2392-2468, 2018.

[19] D. Leech, P. Kavanagh, and W. Schuhmann, "Enzymatic fuel cells: Recent progress," Electrochimica Acta, vol. 84, pp. 223-234, 2012

[20] M. Cadet, S. Gounel, C. Stines-Chaumeil, X. Brilland, J. Rouhana, F. Louerat, et al., "An enzymatic glucose/O2 biofuel cell operating in human blood," Biosensors Bioelectron., vol. 83, pp. 60-67, 2016.

[21] I. Mazurenko, A. de Poulpiquet, and E. Lojou, "Recent developments in high surface area bioelectrodes for enzymatic fuel cells," Curr. Opin. Electrochem., vol. 5, pp. 74-84, 2017.

[22] A. J. Gross, M. Holzinger, and S. Cosnier, "Buckypaper bioelectrodes: emerging materials for implantable and wearable biofuel cells," Energy Environ. Sc., vol. 11, pp. 1670-1687, 2018.

[23] N. Mano, "Recent advances in high surface area electrodes for bioelectrochemical applications," Current Opinion in Electrochemistry, vol. 19, pp. 8-13, 2020.

[24] D. Desmaële, L. Renaud, and S. Tingry, "A wireless sensor powered by a flexible stack of membraneless enzymatic biofuel cells," Sensors Actuators B: Chem., vol. 220, pp. 583-589, 2015.

[25] M. Falk, M. Alcalde, P. N. Bartlett, A. L. De Lacey, L. Gorton, C. Gutierrez-Sanchez, et al., "Self-Powered Wireless Carbohydrate/Oxygen Sensitive Biodevice Based on Radio Signal Transmission," PLoS ONE, vol. 9, p. e109104, 2014.

[26] A. Kobayashi, K. Ikeda, Y. Ogawa, M. Nishizawa, K. Nakazato, and K. Niitsu, "An energy-autonomous bio-sensing system using a biofuel cell and $0.19 \mathrm{~V} 53 \mu \mathrm{W} 65 \mathrm{~nm}-\mathrm{CMOS}$ integrated supplysensing sensor with a supply-insensitive temperature sensor and inductive-coupling transmitter," in 2016 IEEE Biomedical Circuits and Systems Conference (BioCAS), 2016, pp. 148-151.

[27] T. Siepenkoetter, U. Salaj-Kosla, X. Xiao, S. Belochapkine, and E. Magner, "Nanoporous Gold Electrodes with Tuneable Pore Sizes for Bioelectrochemical Applications," Electroanalysis, vol. 28, pp. 24152423, 2016.

[28] A. Karajić, S. Reculusa, S. Ravaine, N. Mano, and A. Kuhn, "Miniaturized Electrochemical Device from Assembled Cylindrical Macroporous Gold Electrodes," ChemElectroChem, vol. 3, pp. 20312035, 2016.

[29] A. Karajic, S. Reculusa, M. Heim, P. Garrigue, S. Ravaine, N. Mano, et al., "Bottom-up Generation of Miniaturized Coaxial Double Electrodes with Tunable Porosity," Adv. Mat. Int., vol. 2, 2015.

[30] F. Gao, L. Viry, M. Maugey, P. Poulin, and N. Mano, "Engineering hybrid nanotube wires for high-power biofuel cells," Nature Communications, vol. 1, p. 2, 2010.

[31] L. Deng, F. Wang, H. Chen, L. Shang, L. Wang, T. Wang, et al., "A biofuel cell with enhanced performance by multilayer biocatalyst immobilized on highly ordered macroporous electrode," Biosensors Bioelectron., vol. 24, pp. 329-333, 2008.

[32] G. Slaughter and T. Kulkarni, "A self-powered glucose biosensing system," Biosensors Bioelectron., vol. 78, pp. 45-50, 2016.

[33] A. F. Yeknami, X. Wang, I. Jeerapan, S. Imani, A. Nikoofard, J. Wang, et al., "A 0.3-V CMOS Biofuel-Cell-Powered Wireless Glucose/Lactate Biosensing System," IEEE Journal of Solid-State Circuits, vol. 53, pp. 3126-3139, 2018.

[34] F. Conzuelo, A. Ruff, and W. Schuhmann, "Self-powered bioelectrochemical devices," Current Opinion in Electrochemistry, vol. 12, pp. 156-163, 2018.

[35] A. Zebda, J.-P. Alcaraz, P. Vadgama, S. Shleev, S. D. Minteer, F. Boucher, et al., "Challenges for successful implantation of biofuel cells," Bioelectrochemistry, vol. 124, pp. 57-72, 2018

[36] S. Cosnier, A. Le Goff, and M. Holzinger, "Towards glucose biofuel cells implanted in human body for powering artificial organs: Review," Electrochemistry Communications, vol. 38, pp. 19-23, 2014

[37] M. Falk, C. W. Narváez Villarrubia, S. Babanova, P. Atanassov, and S. Shleev, "Biofuel Cells for Biomedical Applications: Colonizing the Animal Kingdom," ChemPhysChem, vol. 14, pp. 2045-2058, 2013. 
[38] P. Cinquin, C. Gondran, F. Giroud, S. Mazabrard, A. Pellissier, F. Boucher, et al., "A Glucose BioFuel Cell Implanted in Rats," PLOS ONE, vol. 5, p. e10476, 2010.

[39] A. Zebda, S. Cosnier, J. P. Alcaraz, M. Holzinger, A. Le Goff, C. Gondran, et al., "Single Glucose Biofuel Cells Implanted in Rats Power Electronic Devices," Scientific Reports, vol. 3, p. 1516, 2013.

[40] S. El Ichi-Ribault, J.-P. Alcaraz, F. Boucher, B. Boutaud, R. Dalmolin, J. Boutonnat, et al., "Remote wireless control of an enzymatic biofuel cell implanted in a rabbit for 2 months," Electrochimica Acta, vol. 269, pp. 360-366, 2018

[41] A. P. Sample, D. J. Yeager, P. S. Powledge, A. V. Mamishev, and J. R. Smith, "Design of an RFID-Based Battery-Free Programmable Sensing Platform," IEEE Trans. Instrum. Meas., vol. 57, pp. 26082615, 2008.

[42] S. Amendola, G. Bovesecchi, A. Palombi, P. Coppa, and G. Marrocco, "Design, Calibration and Experimentation of an Epidermal RFID Sensor for Remote Temperature Monitoring," IEEE Sensors Journal, vol. 16, pp. 7250-7257, 2016.

[43] S. Milici, S. Amendola, A. Bianco, and G. Marrocco, "Epidermal RFID passive sensor for body temperature measurements," in 2014 IEEE RFID Technology and Applications Conference (RFID-TA), 2014, pp. 140-144.

[44] AMS. (2018). SL900A tag chip datasheet [Online]. Available: https://ams.com/documents/20143/36005/SL900A DS000294 500.pdf/d399f354-b0b6-146f-6e98-b124826bd737

[45] EM-Microelectronics. (2019). EM4325 tag chip datasheet [Onlne]. Available:

https://www.emmicroelectronic.com/sites/default/files/products/datas heets/4325-ds 0.pdf

[46] J. S. Besnoff, T. Deyle, R. R. Harrison, and M. S. Reynolds, "Battery-free multichannel digital ECG biotelemetry using UHF RFID techniques," in 2013 IEEE International Conference on RFID (RFID), 2013, pp. 16-22.

[47] A. Dementyev and J. R. Smith, "A wearable UHF RFID-based EEG system," in 2013 IEEE International Conference on RFID (RFID), 2013, pp. 1-7.

[48] X. Lin and B. Seet, "Battery-Free Smart Sock for Abnormal Relative Plantar Pressure Monitoring," IEEE Trans. Biomed. Circuits Syst., vol. 11, pp. 464-473, 2017.

[49] A. Wickramasinghe, D. C. Ranasinghe, C. Fumeaux, K. D. Hill, and R. Visvanathan, "Sequence Learning with Passive RFID Sensors for Real-Time Bed-Egress Recognition in Older People," IEEE Journal of Biomedical and Health Informatics, vol. 21, pp. 917-929, 2017.

[50] M. C. Caccami, M. Y. S. Mulla, C. D. Natale, and G. Marrocco, "Graphene oxide-based radiofrequency identification wearable sensor for breath monitoring," IET Microwaves, Antennas \& Propagation, vol. 12, pp. 467-471, 2018.

[51] S. Nappi, V. Mazzaracchio, L. Fiore, F. Arduini, and G. Marrocco, "Flexible pH Sensor for Wireless Monitoring of the Human Skin from the Medimun Distances," in 2019 IEEE International Conference on Flexible and Printable Sensors and Systems (FLEPS), 2019, pp. 1-3.

[52] L. Di Trocchio, J.-L. Lachaud, O. Chassande, C. Dejous, A. Kuhn, and S. Hemour, "Wireless Power Transfer Link for RFID Telemetry System Applied to Laboratory Rodent Monitoring," in 2018 IEEE Wireless Power Transfer Conference (WPTC), 2018

[53] D.-H. Kim, N. Lu, R. Ma, Y.-S. Kim, R.-H. Kim, S. Wang, et al., "Epidermal Electronics," Science, vol. 333, pp. 838-843, 2011

[54] J. A. Rogers, R. Ghaffari, and D.-H. Kim, Stretchable Bioelectronics for Medical Devices and Systems, 1 ed.: Springer International Publishing, 2016.

[55] N. Mano, F. Mao, and A. Heller, "Characteristics of a Miniature Compartment-less Glucose- $\mathrm{O} 2$ Biofuel Cell and Its Operation in a Living Plant," J. Am. Chem. Soc., vol. 125, pp. 6588-6594, 2003.

[56] C. Miozzi, S. Nappi, S. Amendola, and G. Marrocco, "A GeneralPurpose Small RFID Epidermal Datalogger for Continuous Human Skin Monitoring in Mobility," in 2018 IEEE/MTT-S International Microwave Symposium - IMS, 2018, pp. 371-373.

[57] P. Mei, B. Krusor, D. E. Schwartz, T. N. Ng, G. Daniel, S. Ready, et al., "Digital Fabrication and Integration of a Flexible Wireless Sensing Device," IEEE Sensors Journal, vol. 17, pp. 7114-7122, 2017.

[58] L. Ardoino, V. Lopresto, S. Mancini, C. Marino, R. Pinto, and G. A Lovisolo, "A radio-frequency system for in vivo pilot experiments aimed at the studies on biological effects of electromagnetic fields," Phys Med Biol, vol. 50, pp. 3643-54, 2005.

[59] C. Gabriel, S. Gabriel, and E. Corthout, "The dielectric properties of biological tissues: I. Literature survey," Physics in Medicine \& Biology, vol. 41, p. 2231, 1996.

[60] S. M. Smith and M. J. Zirwas, "Nonallergic Reactions to Medical Tapes," Dermatitis, vol. 26, pp. 38-43, 2015.

[61] P. V. Nikitin, K. V. S. Rao, S. F. Lam, V. Pillai, R. Martinez, and H. Heinrich, "Power reflection coefficient analysis for complex impedances in RFID tag design," IEEE Trans. Microwave Theory Tech., vol. 53, pp. 2721-2725, 2005.

[62] N. Mano, "Engineering glucose oxidase for bioelectrochemical applications," Bioelectrochemistry, vol. 128, pp. 218-240, 2019.

[63] N. Mano and L. Edembe, "Bilirubin oxidases in bioelectrochemistry:Features and recent findings," Biosens Bioelectron, vol. 50, pp. 478-485, 2013.

[64] A. Heller, "Electrical wiring of redox enzymes," Acc. Chem. Res., vol. 23, pp. 128-134, 1990.

[65] S. Reculusa, M. Heim, F. Gao, N. Mano, S. Ravaine, and A. Kuhn, "Design of Catalytically Active Cylindrical and Macroporous Gold Microelectrodes," Advanced Functional Materials, vol. 21, pp. 691698, 2011.

[66] F. A. Al-Lolage, P. N. Bartlett, S. Gounel, P. Staigre, and N. Mano, "Site-Directed Immobilization of Bilirubin Oxidase for Electrocatalytic Oxygen Reduction," ACS Catalysis, pp. 2068-2078, 2019

[67] L. Zhang, C. Carucci, S. Reculusa, B. Goudeau, P. Lefrançois, S. Gounel, et al., "Rational Design of Enzyme-Modified Electrodes for Optimized Bioelectrocatalytic Activity," ChemElectroChem, vol. 6, pp. 4980-4984, 2019

[68] A. Heller, "Electron-conducting redox hydrogels: design, characteristics and synthesis," Curr. Opin. Chem. Biol., vol. 10, pp. 664-672, 2006

[69] A. Ruff, "Redox polymers in bioelectrochemistry: Common playgrounds and novel concepts," Curr. Opin. Electrochem., vol. 5, pp. 66-73, 2017.

[70] N. Mano, F. Mao, and A. Heller, "Characteristics of a miniature compartment-less glucose-O2 biofuel cell and its operation in a living plant," J. Am. Chem. Soc., vol. 125, pp. 6588-94, 2003.

[71] O. Courjean, V. Flexer, A. Prevoteau, E. Suraniti, and N. Mano, "Effect of degree of glycosylation on charge of glucose oxidase and redox hydrogel catalytic efficiency," ChemPhysChem, vol. 11, pp. 2795-7, 2010.

[72] K. F. Gey, "The concentration of glucose in rat tissues," The Biochemical journal, vol. 64, pp. 145-150, 1956.

[73] C. P.G., "Eating," in The Behavior of the Laboratory Rat: A Handbook with Tests, Ian Q. Whishaw and B. Kolb, Eds., ed: Oxford University Press, 2004, pp. 197-205.

[74] C. J. Gordon, "Thermal biology of the laboratory rat," Physiol. Behav., vol. 47, pp. 963-991, 1990.

[75] M. Ruiter, S. E. La Fleur, C. van Heijningen, J. van der Vliet, A. Kalsbeek, and R. M. Buijs, "The Daily Rhythm in Plasma Glucagon Concentrations in the Rat Is Modulated by the Biological Clock and by Feeding Behavior," Diabetes, vol. 52, pp. 1709-1715, 2003

[76] Y. Adamovich, B. Ladeuix, M. Golik, M. P. Koeners, and G. Asher, "Rhythmic Oxygen Levels Reset Circadian Clocks through HIF1 $\alpha$," Cell Metabolism, vol. 25, pp. 93-101, 2017.

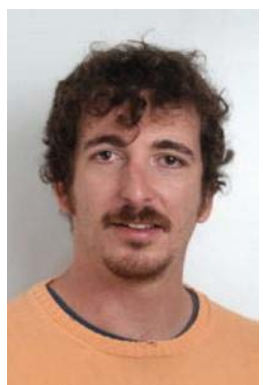

Luigi Di Trocchio received the B.Sc. and M.Sc. degrees in electronic engineering from the University of Rome "la Sapienza", Italy in 2013 and 2016 respectevely, and the Ph.D. degree in electronics from the University of Bordeaux, France in 2019

In 2013, he was with the Laboratory of Electromagnetic Fields of the ENEA Casaccia research center, Rome, Italy, where he was a member of the electromagnetic compatibility team. In 2016, he was with the Core Facilities, Istituto Superiore di Sanità, Rome, Italy and with the National Institute for Nuclear Physics (INFN), Rome, Italy where he was involved in the X-BAnd resonator for Non-Descrutive EPR (Electron 
Paramagnetic Resonance) measurements (XBANDE) project. In December 2016, he joined the University of Bordeaux, France, as a PhD student, working on wireless micro energy solutions for IoT and biomedical applications. His current research interests include wireless power transfer and hybrid energy harvesting for wearable and implantable wireless medical devices, wearable antenna design, RFID sensors for biomedical applications, interactions between electromagnetic fields and biological tissues.

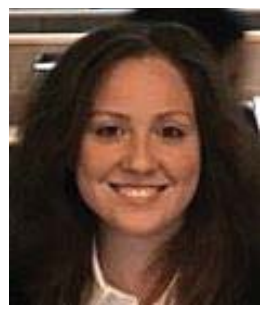

Cristina Carucci was born in Cagliari, Italy, in 1990. She received the B.Sc. and M.Sc. degrees in chemistry from the University of Cagliari, Italy in 2012 and 2014 respectevely, and the $\mathrm{Ph} . \mathrm{D}$. degree from the University of Limerick, Ireland in 2018

In 2018, she was recruited as post-doctoral researcher at the Université de Bordeaux (France) working between the "NanoSystèmes Analytiques" and the "Centre de Recherche Paul Pascal" in Bordeaux. Her research interests focus on biophysical chemistry, enzyme immobilization, support materials such as ordered macroporous gold electrodes and nanomaterials design for drug delivery.

Sindhu Kotagudda Ranganath received the B.S. and M.S. degrees in pharmacy from the Rajiv Gandhi University, Bangalore, India, in 2010 and 2013 respectively, and the Ph.D. degree in cell biology from University of Bordeaux, France in 2019.

Presently, she is working as a post-doctoral researcher at the University of Lille France. Her research interest includes the Preclinical small animal models, Biomaterial and Tissue characterization techniques for biocompatibility studies.

Chloé Morel was born in France in 1992. She received a B.S. degree in analytical and experimental biology from the IUT NANCY-BRABOIS, Vandoeuvre les Nancy, France in 2014.

From 2017 to 2018, she was with the research unit BFA-UMR ParisDiderot, Paris, France. In 2019, she joined the Inserm unit BioTis, Bordeaux, France as an assistant engineer. Her research interests focus on the foreign body reaction to implanted medical devices or biosensors.

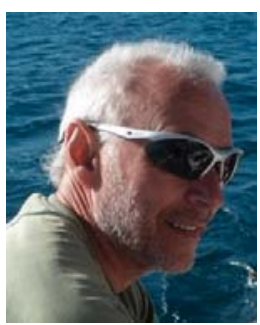

Jean-Luc Lachaud was born in 1959 in France. He received electronic engineer degree (C.N.A.M Bordeaux) in 2005.

After 8 years in electronic companies, he was with the University of Bordeaux, France, for 10 years as electronician at a physiology laboratory. He joined the CNRS in 2001 and works at the Laboratory of Integration from Material to System (IMS, CNRS UMR 5218) of the University of Bordeaux. He was promoted as Engineer then Research Engineer in 2008 and 2018 , respectively. He mainly works on experimental set-up development for test and characterization.

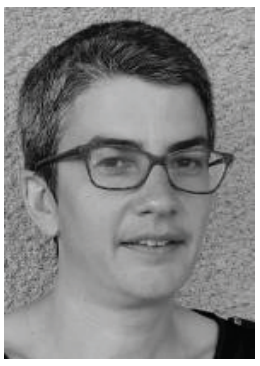

Sabrina Bichon was born in Nantes, France in 1979. She received the Associate Degree in chemistry from the University of Maine, Le Mans, France in 1999

From 2000 to 2002, she was a technician at Corning SAS Avon. From 2002 to 2007, she joined the Ministry of Equipment as a technician at the Laboratoire des Matériaux et Structures du Génie Civil (UMR 113). In 2007, she joined the CNRS as a technician at the laboratory Environnement et Paléoenvironnements Océaniques et Continentaux (UMR 5805). She later joined the Centre de Recherche Paul Pascal (UMR 5031) in 2015. She became technician superior in 2017 and was promoted Assistant Engineer in 2018. She is coauthor of 22 papers and one patent. Her research interests include oceanography, environmental chemistry, (bio)electrochemistry, polymer chemistry, biofuel cells and biosensors.

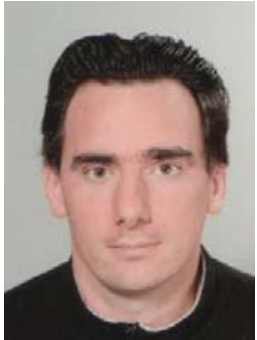

Sébastien Gounel was born in Lyon, France in 1981. He received an engineer degree in biological development from the « Ecole Pratique des Hautes Etdudes » of Paris in 2005.

From 2005 to 2008, he was an engineer at Lyon sud hospital. In 2008, he was recruited as an engineer at the Centre National de Recherche Scientifique (CNRS) within the «Biopiles et Biocapteurs » team at the "Centre de Recherche Paul Pascal » in Bordeaux. He is the author of more than 30 articles and 2 patents. His research interests include molecular biology, bioinformatics, enzyme engineering and enzymatic production to improve enzymes for biosensors and biofuel cells applications

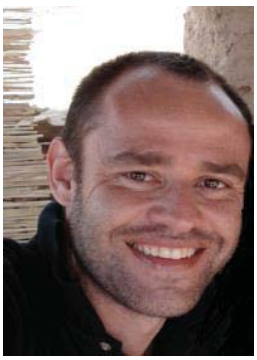

Nicolas Mano was born in Arcachon, France in 1973. He received the B.S. and M.S. degrees in physical chemistry and environmental chemistry from the University of Bordeaux, France, in 1997 and the Ph.D. degree in Physical Chemistry from the University of Bordeaux, France, in 2001.

From 2001 to 2006, he was first post-doc then Research Associate at the University of Texas at Austin (Dpt of chemical engineering) working with Prof A. Heller. In 2006, he joined the CNRS as a junior scientist at the Centre de Recherche Paul Pascal (UMR 5031) in Bordeaux, France and was promoted Senior researcher in 2012. He is the author of more than 130 articles, and 15 inventions. His research interests include (bio)electrochemistry, biosensors, biofuel cells, enzymes engineering, and the use of carbonaceous materials for electrodes.

His contributions to these fields has been recognized by many national and international prizes and awards including a ERC starting grant in 2006, the Luigi Galvani prize of the Bioelectrochemical Society and the Oronzio de Nora Prize of the International Society of Electrochemistry.

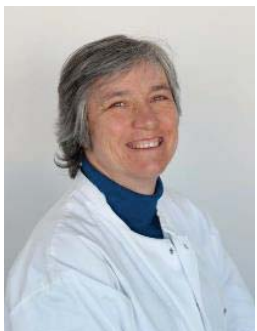

Claudine Boiziau was born in 1964 in Palaiseau (France). After graduation as Engineer of ENSTAParisTech (Paris, France) in 1988, she received the $\mathrm{PhD}$ degree of Molecular and Cellular Pharmacology from the University Pierre-etMarie-Curie, Paris, France in 1991.

She was hired as a researcher at the Inserm (public research organization in France dedicated to human health) in 1993. Since then, she is working as a researcher at the University of Bordeaux, France. From 1990 to 2003, she was working on the artificial control of gene expression with oligonucleotides. Then, she joined an Inserm unit working on the human inflammatory disease multiple sclerosis and analyzed the role of specific cells (macrophages) in the inflammation regulation. Since 2013, she has joined the Inserm unit BioTis, developing biomaterials for tissue regeneration. Her research axes are focused on the host inflammatory responses after implantation of a medical device.

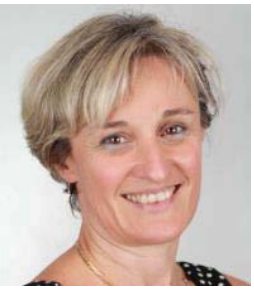

Corinne Dejous (M'13) received the electronics engineer degree from the French "Grande Ecole" ENSEIRB in 1991 (M.S. degree), and the Ph.D. degree in electronics from the University of Bordeaux, France, in 1994.

In 1996, she has been appointed Assistant Professor at the University of Bordeaux, and promoted in 2009 to Full Professor at ENSEIRBMATMECA / Bordeaux INP, France, where she teaches electronic systems and instrumentation, chemical sensors and microsystems. She leads research at IMS laboratory (CNRS UMR 5218) in acoustic wave (bio)chemical microsensors and more generally wave-based resonant sensors, her research activities also include wireless microdevices. Major fields of applications aim health and environment purposes. She has been the head of the research group Ondes (Waves, formerly Microsystems) from 2011 to 2018. From 2016, she is in charge of the IMS Labs' transverse topic « Environments ».

She co-authored over 70 publications in international journals or book chapters, more than 180 communications, and co-supervised 35 research 
projects. She is also involved in the French Chapter of the IEEE Sensors Council.

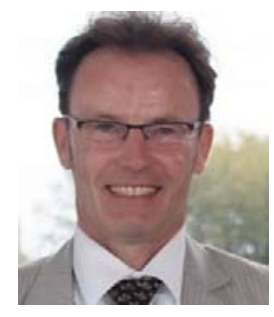

Alexander Kuhn was born in Aising, Bavaria, Germany in 1965. He received the M.S. degree in chemistry from the Technical University of Munich in 1991, and the Ph.D. degree in physical chemistry from the University of Bordeaux, France, in 1994.

From 1995 to 1996 , he was a post-doc at the California Institute of Technology, Pasadena, USA. In 1996 he was appointed Assistant Professor at the University of Bordeaux, France and promoted to Full Professor at ENSCBP, France, in 2000. He is the author of more than 200 publications. His research interests include molecular surface modification of electrodes, meso- and macroporous electrodes, (bio)electroanalysis, (bio)electrocatalysis, bipolar electrochemistry, electrodeposition, micro- and nanoelectrodes Janus particles and chirality.

Prof. Kuhn is a senior member of the Institut Universitaire de France, distinguished senior fellow of the French Chemical Society, member of the editorial board of several journals and has received various scientific recognitions including an ERC Advanced grant for his project ELECTRA. He also holds positions as Adjunct Professor at VISTEC University (Thailand) and Henan University (China).

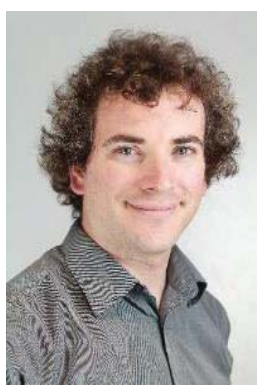

Simon Hemour (S'08-M'11-SM'16) received the B.S. degree in electrical engineering from the University of Grenoble Alpes, Grenoble, France, in 2004, and the M.S. and Ph.D. degrees in optics, optoelectronics, and microwave engineering from the Grenoble Institute of Technology, Grenoble, France, in 2006 and 2010, respectively.

In 2003, he was with the European Organization for Nuclear Research, Geneva, Switzerland, as a member of the Instrumentation Department, where he was involved in ATLAS experiment on the Large Hadron Collider. From 2006 to 2007, he was a Research Assistant with the Pidstryhach Institute of Applied Problems of Mechanics and Mathematics, National Academy of Science of Ukraine, Lviv, Ukraine. In 2007, he joined the IMEP-LAHC MINATEC Laboratory, Grenoble, France. From 2011 to 2015, he was with the PolyGrames Research Center, École Polytechnique de Montréal, Montréal, QC, Canada, where he was leading the Wireless Power Transmission and Harvesting Research Group. He joined the Université de Bordeaux, Bordeaux, France, in 2015, where he is currently an Associate Professor, and he leads research in wireless micro energy solutions for IoT and biomedical applications. His current research interests include wireless power transfer and hybrid energy harvesting, backscattering, nonlinear devices, innovative RF measurements, RF interferometry, low power microwave, and millimeterwave conversion circuits, development of RF transponders and sensors for wireless systems and biomedical applications.

Dr. Hemour is a member of the IEEE MTT-26 Wireless Energy Transfer and Conversion Technical Committee and of the IEEE MTT-10 Biological effect and medical application Technical Committee. He has been invited to give many invited talks and plenary speeches at various international meetings, conferences and forums, and his pioneering work on low power RF energy harvesting has been highly cited. He was the TPC chair of the 2018 Wireless Power Transfer Conference. He is part of the Editorial Board of the Wireless Power Transfer journal (Cambridge University press), and he has served as guest editor for IEEE Transactions on Microwave Theory and Techniques, as well as for the IEEE Journal of Electromagnetics, RF and Microwaves in Medicine and Biology 